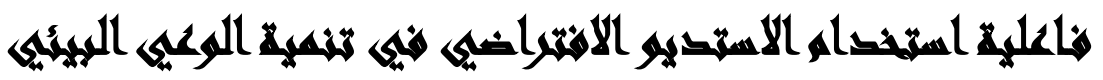

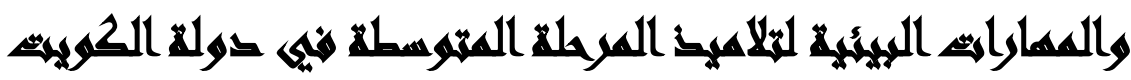 [rY]
}

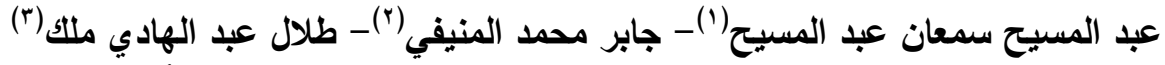

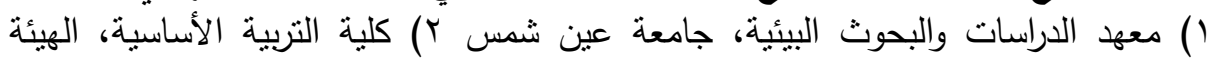

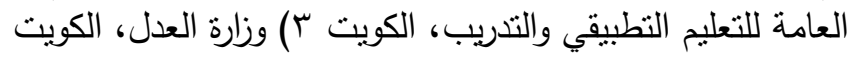

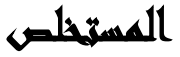

هدف البحث إلى تتمية الوعي البيئي والمهارات البيئية لدى تلاميذ المرحلة المتوسطة في

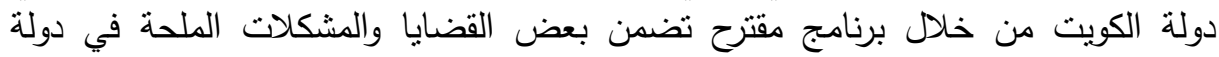

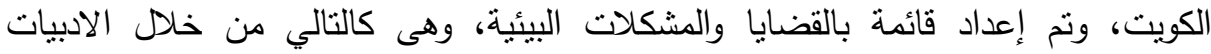

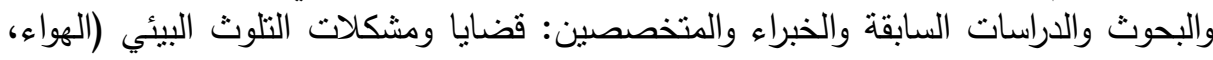

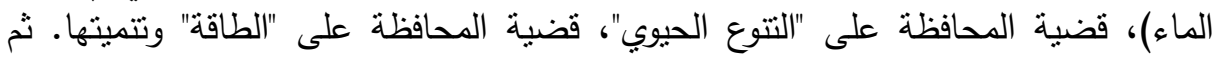

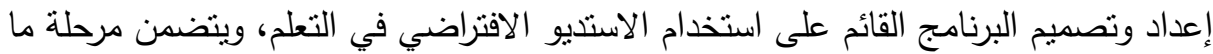

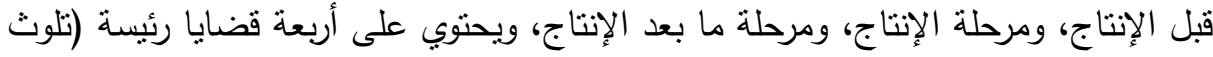

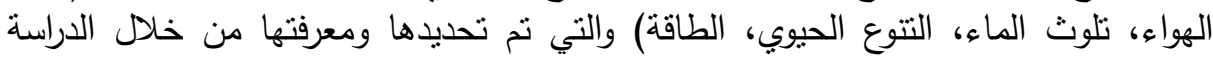

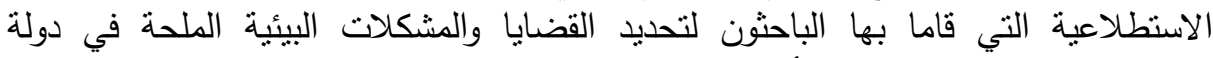

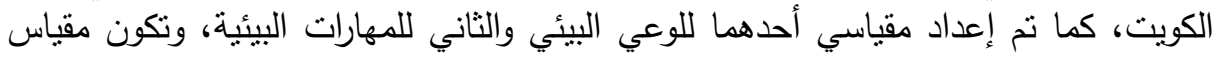

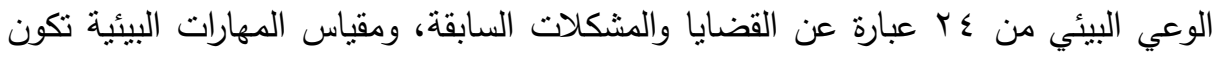

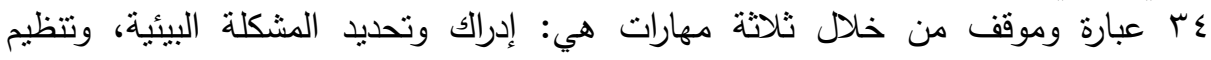

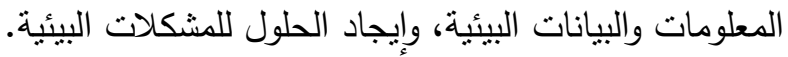

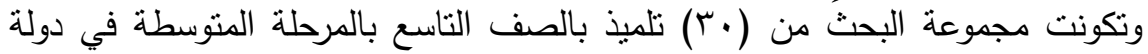

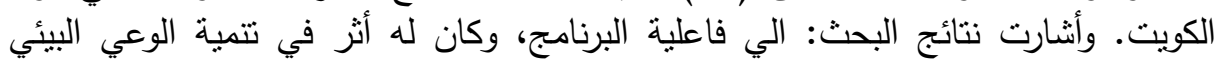
والمهارات البيئية لهؤلاء التلاميذ. نانج 


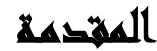

"إن الأرض هي أم الإنسانية، وإن إفساد البيئة يعتبر عقوقاً لأمنا الأرض، وإضاعة

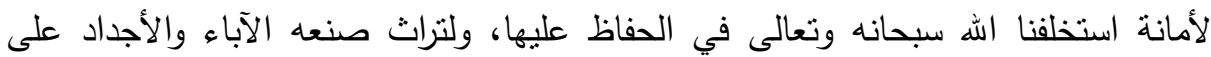

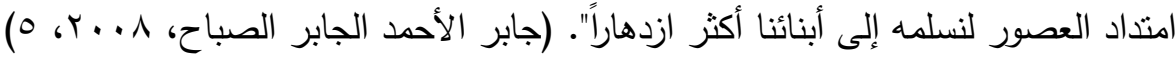

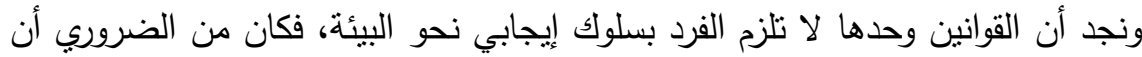
يعضدها الوعى والإدراك الذى يصل إلى ضمير الإنسان فيعمل على تكوين اتجاهاته وقيمه الإيجابية وسلوكه الذى يحافظ من خلاله على البيئة، ولا يتم تكوين تلك الاتجاهات والقيم إلا لإلا لإلى بحسن إعداد الفرد في هذا المجال وتربيته تربية سليمة داخل المؤسسات التعليمية وخارجها •ومن هنا " كان على التربية أن نقوم بدورها في مواجهة تلك المشكلات البيئية ، حتى يتم الحد من تزايدها وتفاقمها وذلك عن طريق توعية المواطنين بالمشكلات التي تضر البيئة والتي

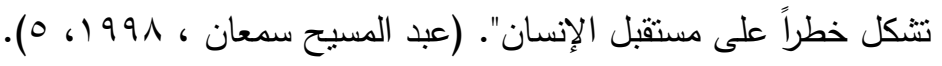
عظم الاهتمام بالبرامج المدرسية وزادت محاولات السعي لتطويرها والارتقاء بها، وذلك الإن ربطاً طرديًا بين تقدمها وتطورها وبين وضعية المجتمع ، وخاصة بعد الطفرة الهائلة في مجال التكنولوجيا وما ترتب عليه من تعاظم دور البرامج المدرسية في مواكبة ذلك التطور ، ونظراً

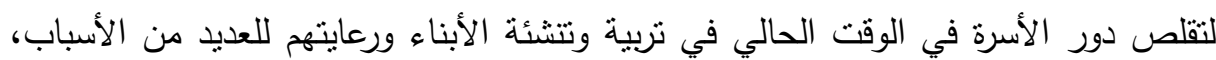
مما ترتب عليه عدم وجود وقت كاف للقيام بالتتشئة السليمة كما كانت من قبل، لذلك تؤكد معظم المصادر والتوجهات تعاظم دور الددرسة في هذا السبيل، ومما يشجع على الاهتمام بدور الددرسة في توعية الأطفال ببيئتهم وكيفية الحفاظ عليها، وان أولى المؤسسات المسئولة عن هذا الثنأن هي المدرسة ،وقد أدي ذلك إلى تطوير برامج الإعداد والتدريبات العملية في

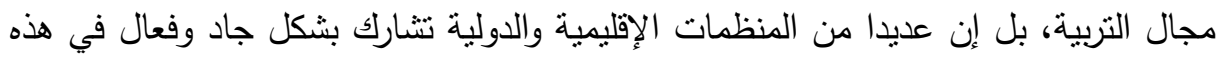

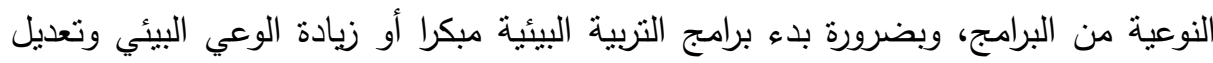

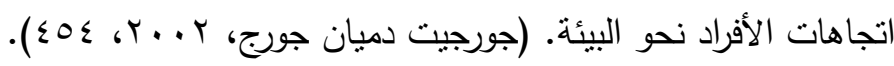


إن توظيف الطاقات البشرية لتتمية الوعي البيئي والمهارات البيئية يمكن أن يشكل لنا

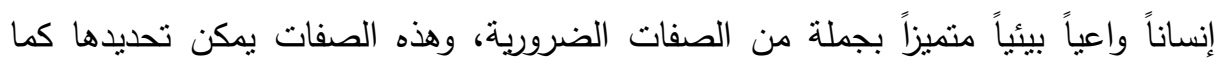

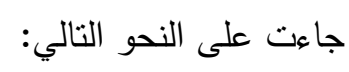
- الإلمام والمعرفة بالمفاهيم البيئية، والمبادئ ذات العلاقئة بهات

- معرفة كيفية تأثنر الانسان على العلاقة بين نوعية الحياة ونوعية البيئة التى يعيش فيها.

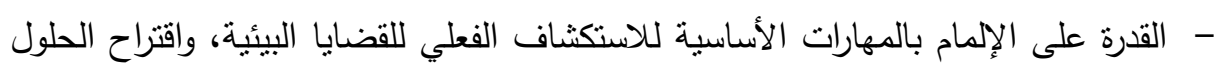

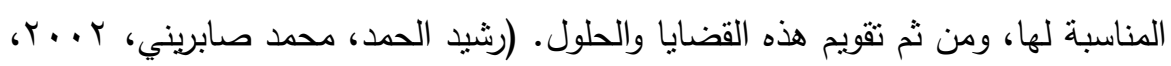

. (rt.

وإذا كان الهدف من التعليم هو تعديل سلوك التلاميذ نحو الأفضل، فالأجدر بنا لتحقيق هذا الغرض تهيئة التلاميذ لتحمل مسئولياتهم نحو حماية البيئة، من خلال تدعيم المناهج الدراسية بموضوعات ذات صلة بالبيئة، حتى يتعرف التلميذ من خلالها على بيئته المحيطة

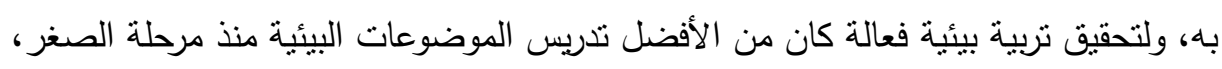

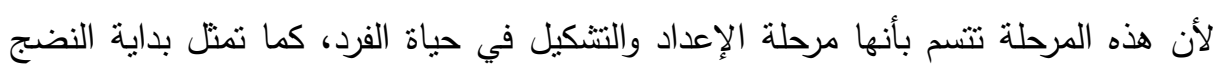

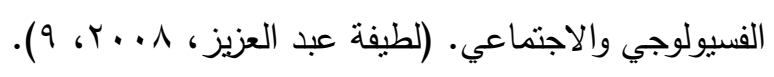
لقد تطورت وتتوعت اساليب استخدام وتوظيف الكمبيوتز في مجال التعليم كما اصبح الكمبيوتر اداة فعالة في تقديم المواد الدراسية التي قد بصعب استيعابها وفهمها واتاحة الفرصة للتكرار والتدريب والممارسة على المهارات المختلفة، ايضاً اصبح الكبيوتر يستخدم كأداة للإدارة التعليمية بهدف تيسير المهارات الادارية والفنية في مؤسسات التعليم، ومن الاتجاهات الحديثة لاستخدام الكمبيوتز في مجال التعليم هو استخدامه كوسيله في انتاج المواد التعليمية كالثفافيات و الصور و الرسوم و الاثكال التخطيطية و الوسائل المتعددة بشكل عام، وانتاج برمجيات تعليمية ذات قيمة و كفاءة مرتفعة لتحقيق اهداف المقررات الدراسية لسنوات تعليمية

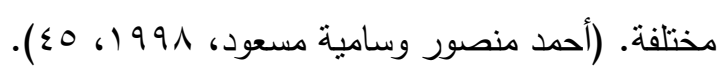


وقد شهدت السنوات الأخيرة طفرة هائلة في المستحدثات التكنولوجية المرتبطة بمجال التعليم، وظهرت مفاهيم جديدة في ميدان التعليم كالتعليم بمساعدة الحاسوب، وتكنولوجيا

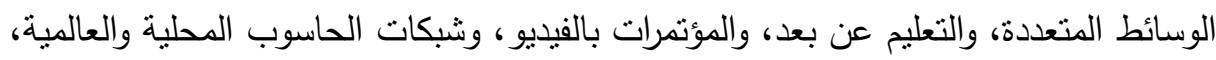
والاستديو الافتراضي، وأصبح واضحاً ضرورة الاستقادة من هذه التكنولوجيات في العملية التعليمية.

ونظراً لما تحتاجه المواقف التعليمية ذات العلاقة بمسألة الوعي البيئي والمهارات البيئية

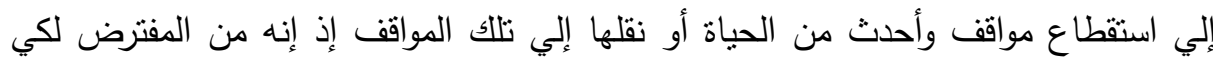

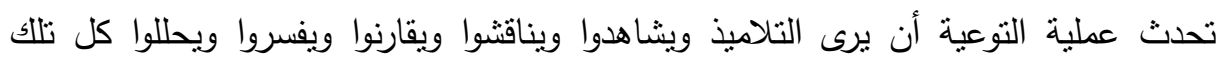
المواقف والأحداث الحياتية، حتي يمكنهم الوصول إلي قرارات معينة ووجهات نظر شخصية بشأن كل موقف، وهو ما ينعكس بشكل مباشر فيما بعد على السلوكيات اليومية لكل تلميذ، والتي تعكس درجة وعيه ومدى مهاراته في التعامل مع القضايا والمشكلات البيئية المختلفة.

\section{And ILan}

قام الباحثون بإجراء دراسة اسنطلاعية للتعرف على (الوعي البيئي و المهارات البيئية) لدى بعض التلاميذ في الكويت حيث تم تطبيق (مقياس الوعي البيئي) من إعداد "فائزة

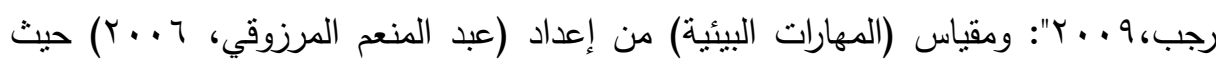
استعان الباحثون بهذه المقياس، وتم توزيعها على مجموعة استطلاعية من تلاميذ المرحلة إعلة

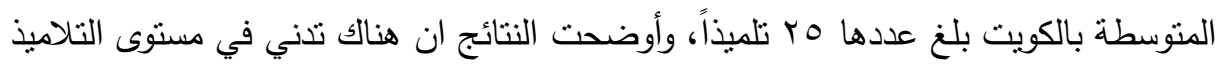

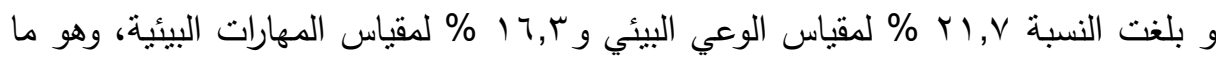
يشير إلي وجود قصور في المناهج التعليمية المقدة لهم لتتمية الوعي البيئي والمهارات البيئية لتلاميذ تلك المرحلة، لذا قام الباحثون بالتعرف على مدى فاعلية استخدام اسلوب الاستديو الافتراضي لتحقيق ذلك. 


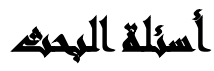

وفى محاولة للتصدي لهذه الششكلة حاول البحث الحالي الإجابة عن السؤال الرئيس الثنالي: "ما فاعلية برنامج قائم على الاستنيو الافتراضي في تلمية الوعي البيئي والههارات البيئية البئية

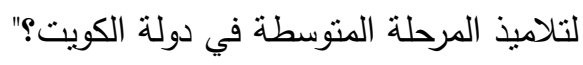
ويتقرع عن هذا السؤال الرئيس الأسئلة الفرعية التالية:

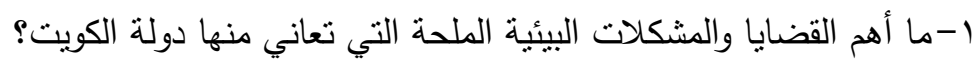

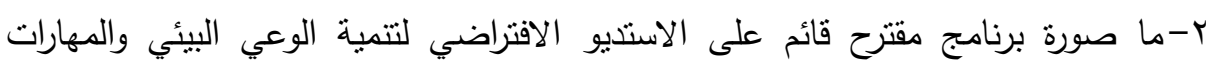
البيئية؟

ז-ما فاعلية البرنامج المقترح فى تتمية الوعي البيئي والمهارات البيئية لدى تلاميذ الصف

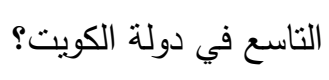

ع -ما فاعلية البرنامج المقترح في تتمية الههارات البيئية للى تلاميذ الصف التاسع في دولة

$$
\text { الكويت؟ }
$$

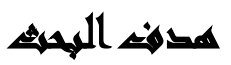

تتمية الوعي البيئي والمهارات البيئية لتلاميذ المرحلة المتوسطة في دولة الكويت من خلال برنامج مقترح قائم على الاستثيو الافتراضي.

\section{هزوضر الهمبه}

توجد فروق ذات دلالة إحصائية في متوسط درجات تلاميذ المجموعة التجريبية في

مقياس الوعي البيئي قبل وبعد تطبيق البرنامج لصالح التطبيق البعدي.

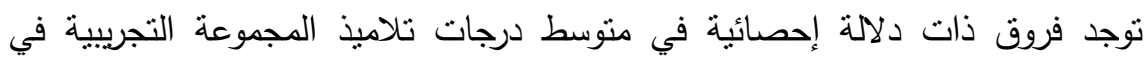

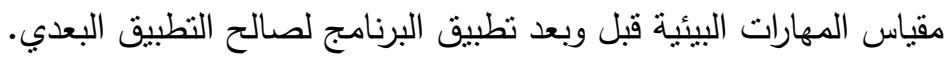




\section{أهمية الهمبش}

$$
\text { قد يستفاد من البحث الحالي فيما يلي: }
$$

1-القائمين على تطوير وتخطيط المناهج الدراسية بالمرحلة المتوسطة بالكويت، باستخدام

الاستديو الافتراضي؛ بما يساهم فى تتمية الوعي البيئي والمهارات البيئية لتلك المرحلة.

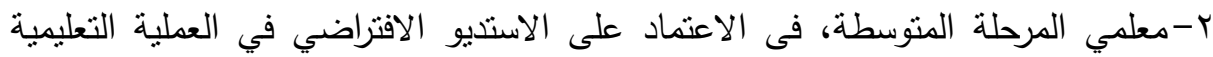

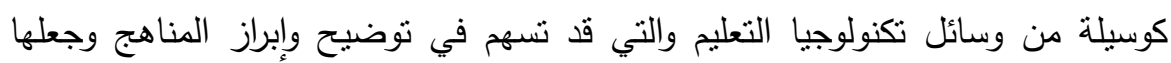
حقائق تتعلق بالحياة والبيئة ومشاكلها المحيطة. ب-يقدم مقياساً فى الوعي البيئي واخر في المهارات البيئية يمكن الاعتماد عليهم، فى قياس وليناس الوعي البيئي والمهارات البيئية، لفئات مختلفة من التناميذ.

\section{منهمج الهميد}

اتبع البحث المنهج شبه التجريبي ذو المجموعة الواحدة (التجريبية) مجموعة البحث

$$
\text { للتأكد من فاعلية البرنامج. }
$$

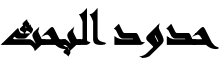

الحدود البشرية: اقتصر البحث على مجموعة بحثية تكونت من (·r) تلمبذاً بالمرحلة المتوسطة بالصف التاسع.

الحدود المكانية: مدرسة "عبد العزيز حسين المتوسطة / بنين بالإدارة العامة لمنطقة العاصمة التعليمية - دولة الكويت.

الحدود الزمنية: تم تطبيق البحث خلال الفصل الدراسي الثاني من العام الدراسي، 10 . 


\section{أسوايت الهمبه}

تمثلت أدوات البحث التي استعان بها الباحثون فيما يلي:

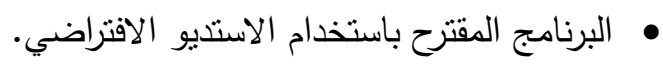

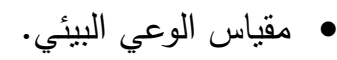
• مقياس المهارات البيئية.

\section{هصطلحاهت المهيد}

الاستثديو الافتراضي: Virtual Studio هو عبارة عن مجموعة تاميم ثلاثنية الأبعاد مع بعضها البعض، تولد بشكل الاستديو الحقيقي وتحاكيه ويصمم بالبرامج ثلاثية الأبعاد وهو أقل تكلفة من الاستديو الحقيقي لأنه لا يحتاج لمساحة أو ديكور فكل شيء فيه افتراضي وتخيلي والكاميرا فيه يتم تحريكها في الفراغ ثلاثي الأبعاد داخل الحاسوب. ( Menuka, Gupta (and Kai Huttemann, 2010,p.111 الوعي البيئي: Environmental Awareness هو الإدراك القائم على الإحساس والمعرفة بالعلاقات والمشكلات البيئية من حيث أسبابها وأثارها ووسائل حلها.

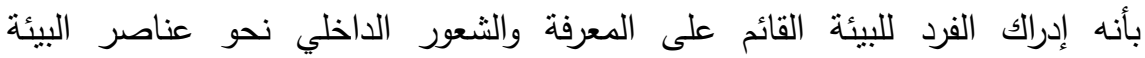
ومشكلاتها، أي لا يكون الاهنمام موجها إلى الذاكرة أو استرجاع المعلومات بقدر الاهنمام بأن

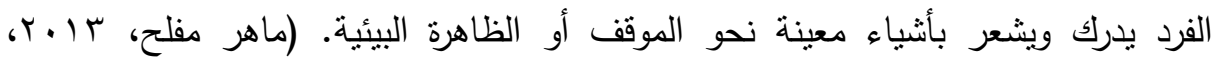

المهارات البيئية: Environmental Skills هى القيام بعمل معين برتبط بالبيئة في أقل

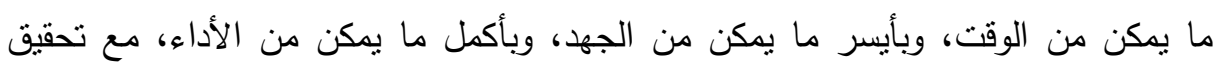
الأمان وتلافي الأضرار أو الأخطاء. وبالتالي فهى مهارات عقلية تقوم على إكساب المتعلمين مهارات حل المشكلات". (صلاح الدين سالم، ع . . r ، 1 ). 


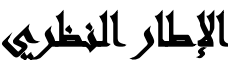

هالوعي البيئي: تشير بعض الدراسات ومنها دراسة (سهام بن يحي، 0. • ب) إلى أن القصور في التعامل مع المشكلات البيئية يكون في الغالب نابع اً من قصور الوعي البيئي

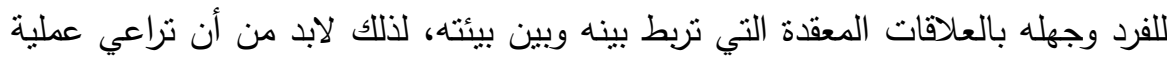

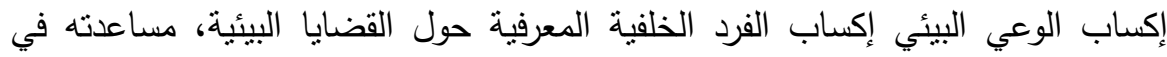
تكوين الاتجاهات الايجابية نحوها، واكسابه المهارات اللازمة للسلوك بطريقة صديقة للبيئة، وهذا لن يتحقق إلا من خلال عملية ممنهجة ومتكاملة في العملية التعليمية برمنها. • المهارات البيئية: تعتبر المهارات البيئية هي أساس التفاعل مع البيئة والعنصر الأساسي للحفاظ على البيئة من النلوث حيث أن المهارة قدرة عالية مكتسبة لأداء الأنشطة

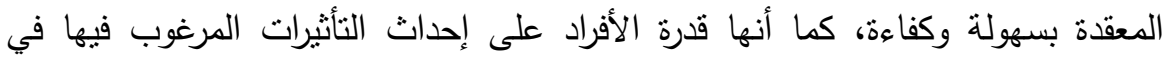
الآخرين والقدرة على إقامة تفاعل اجتماعي ناجح. ( Goldensan RU, 1984, p.181

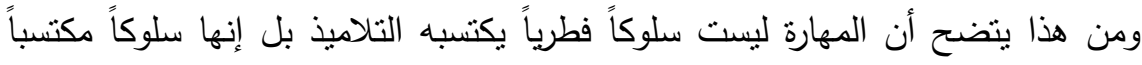

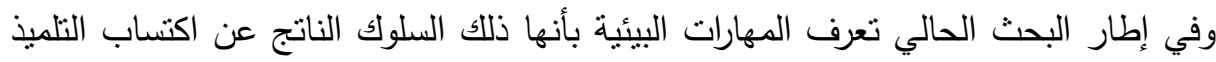

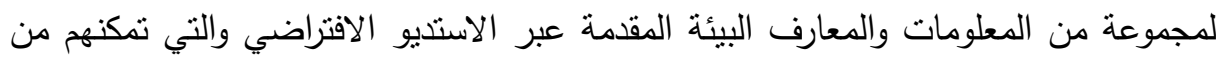
المواجهة الصحيحة للقضايا والمشكلات البيئية الملحة لدولة الكويت واتخاذ موقف أو قرار الئه

$$
\text { إيجابي تجاهها. }
$$

هالاستديو الافتراضي: ان تأثير اللغة البصرية كالسينما والتلفزيون والفيديو جميعها لها تأثنير كبير على المتلقين في كل جوانب حياتهم، فإذا ما تم ادخال هذا الوسائط في الحقل

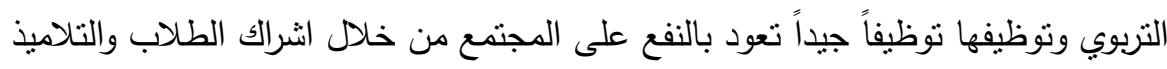
في هذه التكنولوجية الاتصالية عن طريق الاستديو الافتراضي وتدعيمه كنشاط تربوي حاله حال الاذاعة والصحافة المدرسية ويختص في نشر التوعية التربوية الهادفة، ومن ثم دمج البعد البيئي متمثناً في الوعي والمهارات البيئية. 


\section{إلجراعايت الهيه}

أولاً: إعداد قائمة القضايا والمشكلات البيئية المحلة والتي تعاني منها دولة الكويت للإجابة عن السؤال الأول من أسئلة البحث والذي ينص على إعلى ما أهم القضايا والمشكلات البيئية الملحة التي تعاني منها دولة الكويت؟ سارت عملية إعداد القائمة في الخطوات التالية: أ- - تحديد الهدف من إعداد القائمة

ب- تحديد مصادر اثتقاق قائمة القضايا والمشكلات البيئية ج- بناء القائمة المبئية للقضايا والمشكلات البيئية قام الباحثون بإعداد القائمة في صورتها المبدئية من خلال الاطلاع على المراجع والدراسات التي تتشرها مؤسسة الكويت للتقام العلمي، والهيئة العامة للبيئة والذي تنعلق بالقضايا والمشكلات البيئية في دولة الكويت، بالإضافة إلي الاطلاع على بعض وله الداسله الداسات

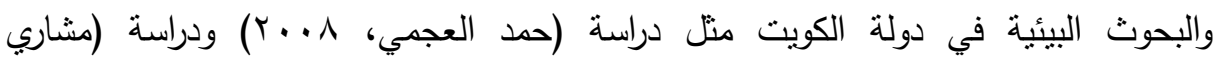

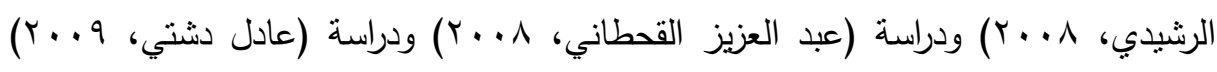

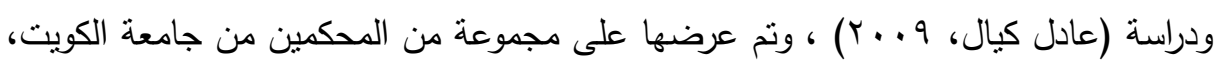
والهيئة العامة للبيئة، والمؤسسات الأهلية، وقد قاموا بإجراء بعض الملاحظات، وتم التعديل في

ضوء هذه الملاحظات، وتم التوصل إلي القائمة التالية:

\begin{tabular}{|c|c|}
\hline الموضوعات المتعلقة بها & القضية والمشكلة البيئية \\
\hline •• • • تُعراع تلوثلث الهواء الهواء & • تلوث الهواء \\
\hline 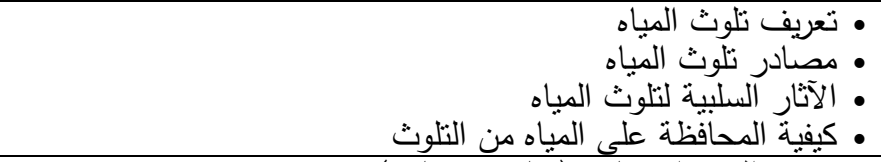 & • تلوث المياه \\
\hline 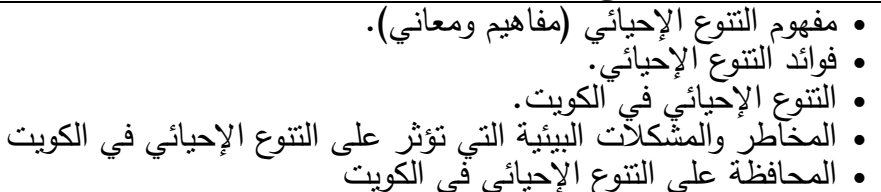 & • • التتوع الحيوي \\
\hline • • • مفصادر الطاقة الطاقة & • الطاقة \\
\hline
\end{tabular}

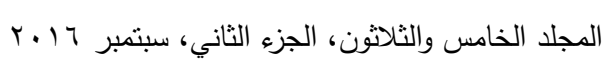


ثانياً: إعداد التصور المقترح لبرنامج باستخدام الاستديو الافتراضي للإجابة عن السؤال الثاني من أسئلة البحث والذي ينص على: ما صورة برنامج مقترح قائم على الاستديو الافتراضي لنتمية الوعي البيئي والمهارات البيئية؟

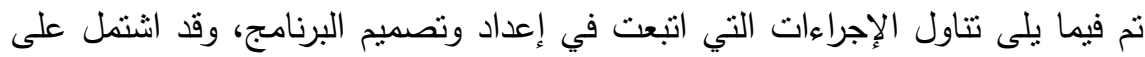
إجراءات إعداد وتصميم البرنامج عدداً من الخطوات، هي:-

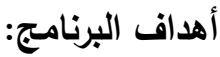
أن يكتسب التلاميذ معلومات عن:

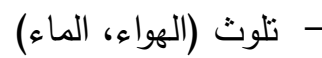

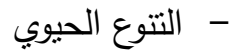

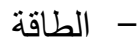

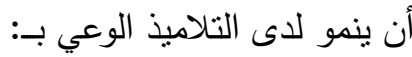
- - بمشكلات النلوث

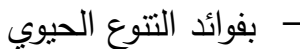

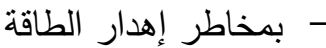

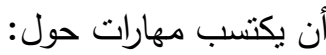
- - الحفاظ على الموارد البيئية من التلوث

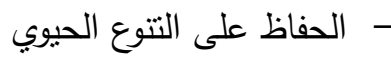
- كيفية التعامل مع البيئة وحل مشكلاتها - التفكير السليم في حل مشكلات وأزمات البيئة - التعاون مع الآخرين لحل مشكلات البيئة

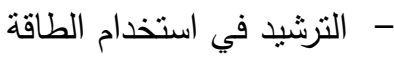
محتوى البرنامج: بعد أن نم تحديد القضايا والمشكلات البيئية التي تعاني منها دول الكوبت

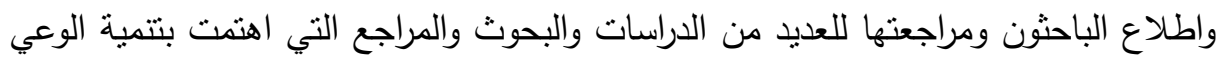
البيئي والمهارات البيئية لدى الطلاب في فئات عمرية مختلفة ومراحل دراسية متعددة كذلك 
المراجع الخاصة في كيفية كتابة السيناريو وصباغته باستخدام الاستديو الافتراضي، فإن البرنامج يتضمن قالب فني يتضمن أربعة قضايا ومشكلات والتي تم تحديدها ومعرفتها من قبل وهي (تلوث الهواء، تلوث المياه، التتوع الحيوي، الطاقة). وبذلك قد تم تحديد وكتابة السيناريو الخاص بالاستديو الافتراضي والذي أمكن القيام به

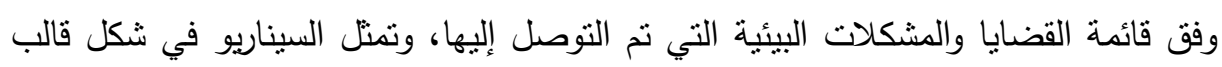
يتألف من الصورة / والنص لكل قضية ومشكلة بالقائمة.

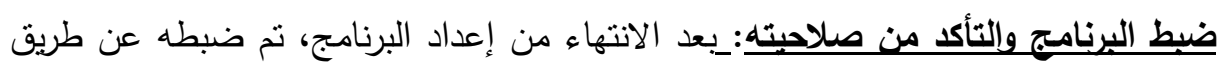

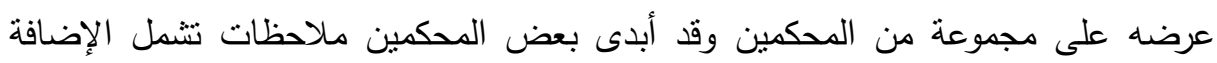
لبعض المقترحات منل (قيام التلاميذ بتحضير وعمل بعض السيناريوهات لمشكلات وقضايا

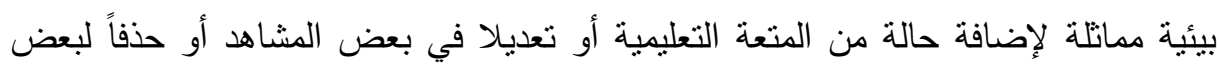
منها التي لا حاجة لها وقد أخذ الباحثون هذه الملاحظات في الاعتبار عند إعادة صياغة الإنها البرنامج وتم إجراء التعديلات اللازمة في البرنامج في ضوء هذه هذه الداء الملاحظات حتي أصبح البرنامج بصورته النهائية جاهزاً للنطبيق. وبذلك قد نمت الإجابة على السؤال الفرعي الثاني من أسئلة البحث وهو : "ما صورة برنامج

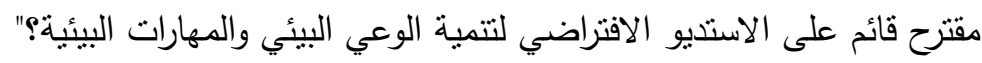
ثالثاً: إعداد مقياسي الوعي البيئي والمهارات البيئية: للإجابة عن السؤال الثالث من أسئلة البحث والذي ينص على: "ما فاعلية البرنامج المقترح فى تتمية الوعي البيئي والمهارات البيئية

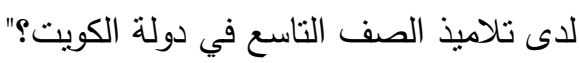
وللتعرف على فاعلية البرنامج المقترح في تتمية الوعي البيئي والمهارات البيئية، كان لابد البد البدات من إعداد مقياس الوعي البيئي وكذلك مقياس المهارات البيئية وضبطهما، وتطبيقهما قبلياً

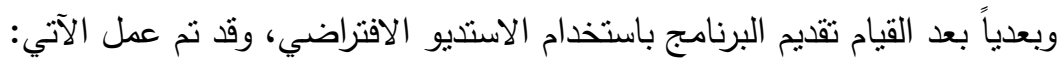

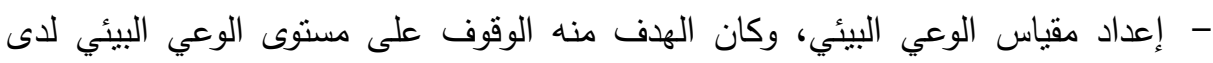
تلاميذ الصف التاسع بالمرحلة المنوسطة. 
- - إعداد مقياس المهارات البيئية، وكان الهدف منه الوقوف على مستوى المهارات البيئية لاى تلاميذ الصف التاسع بالمرحلة المتوسطة. وذللك قبل وبعد تطبيق البرنامج.

وتم الأخذ بأراء المُحكِّمين والتي تمنلت في حذف بعض بعض العبارات وتحويل بعض العبارات

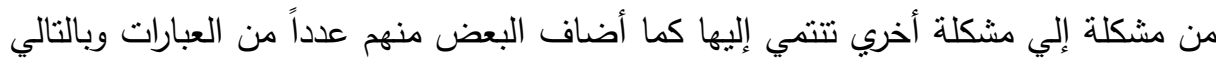

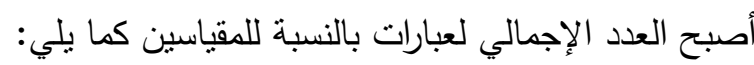

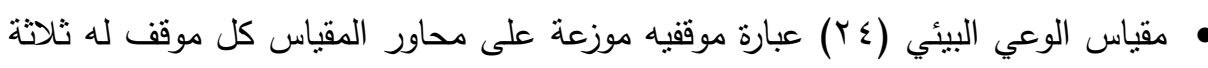
اختيارات، ويتتاول المقياس القضايا والمشكلات البيئية الملحة في دولة الكويت، موركات وكانت (تلوث الهواء، تلوث المياه، التتوع الحيوي، الطاقة). ويكون تقدير الدرجات بأن بعطي لهابه

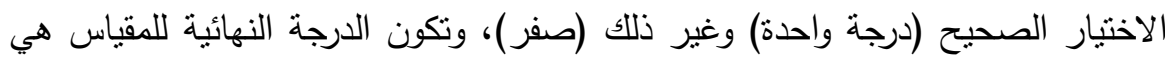

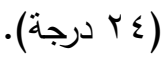
• مقياس المهارات البيئية (ع ب) عبارة موقفيه موزعة على محاور المقياس، وهي كالتالي: - المحور الأول: إدراك المشكلة البيئية، وهدف إلى قياس قدرة التلميذ على على على إدراك وتحديد المشكلة البيئية في الموقف، ونم تقدير الدرجات بأن يعطي للاختيار الصحيح (درجة واحدة، وغير ذلك يعطي صفر)، وتكون هذا المحور من (V V ( V) عبارة موققيه.

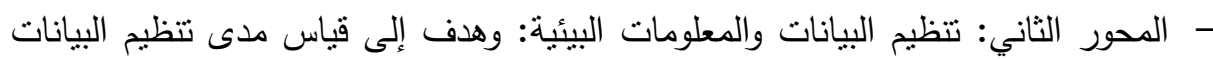

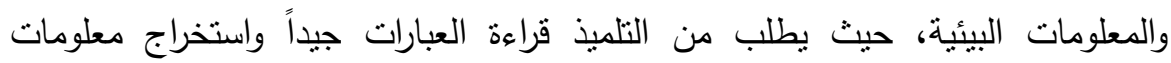
وبيانات نتضمن الإجابات عنها، ونم تقدير الدرجات بأن بعطي للاختيار الصحيح (درجة واحدة، وغير ذلك يعطي صفر )، وتكون هذا المحور من (V) عبارة موقفيه.

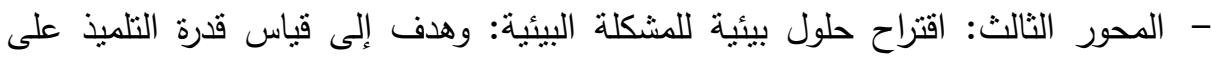
إيجاد الحلول المناسبة أو البديلة للمشكلات البيئية، وقد تم صياغة هذا المحور من خلائل وهلئل مجموعة من العبارات التي تمنل كلاً منها مشكلة بيئية ويطلب من التلميذ اقتراح الحلول مله المناسبة، ونم تقدير الدرجات بأن يعطى للتلميذ (درجة واحدة) في حالة اعطاء التلميذ لحل 
واحد، اما في حالة اعطائه لحلين فانه يعطى (درجتان) على كل موقف، في حالة الاجابة غير صحيحة يعطى (صفر)، وتكون هذا المحور من (· (1) عبارة موقفيه. - وعلى ذلك تكون الدرجة الكلية للمقياس (ع ؟) درجة.

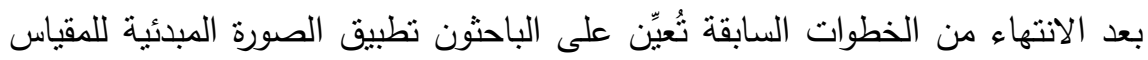
وذللك للنأكد من: ثبات المقياس وصدقه.

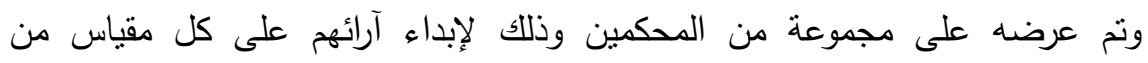
المقياسين، وفي مدى مناسبة كل مقياس لمستوى تلاميذ المرحلة المتوسطة، بعد ذلك نم تطبيقه

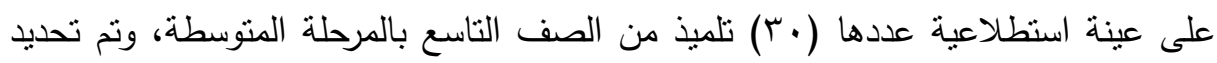
الزمن المناسب للإجابة على مقياس الوعي البيئي وهو (·ץ) دقيقة، ومقياس المهارات البيئية وهو (ك0) دقيقة. وبذلك يكون الباحثون قد أتموا إعداد أدوات البحث وضبطها والتحقق من صلاحيتها للتطبيق. وأصبحت المقاييس في صورتها النهائية وصالحة للنطبيق على طلاب الددارس بالمرحلة المتوسطة "بالصف التاسع". إجراء الاراسة الميدانية:

تطبيق أدوات البحث قبليا: بعد التأكد من صدق المقياسين وثباتهما، تم تطبيقهما قبل دراسة البرنامج من قبل مجموعة الدراسة. تم القيام بإجراءات التطبيق الميداني التالية:

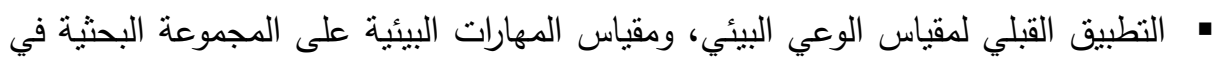

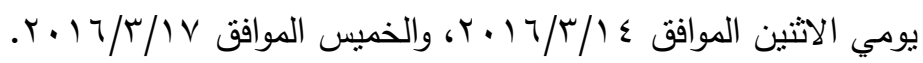

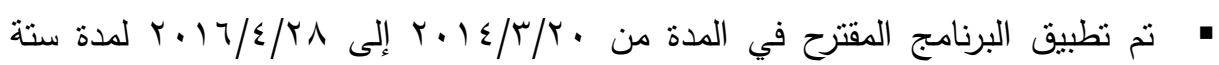

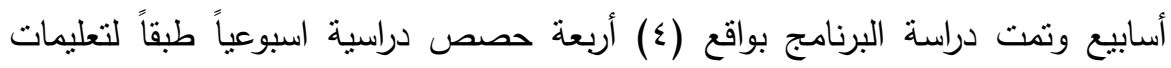
المدرسة بذلك، حتى لا تتعارض مع العملية التعليمة بالمدرسة، وتم التطبيق من خلال

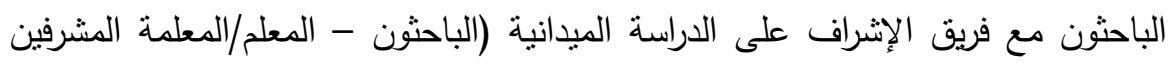

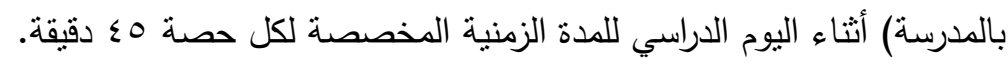


• بعد أن ثم عرض البرنامج على المحكمين بغرض معرفة آرائهم حول مناسبة البرنامج،

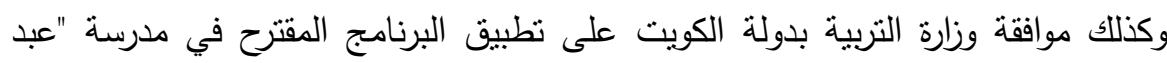

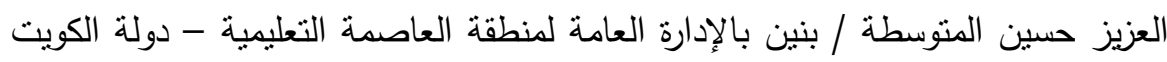
التي نم فيها نطبيق البرنامج المقترح وقام الباحثون بنطبيق البرنامج ومثابعة التطبيق

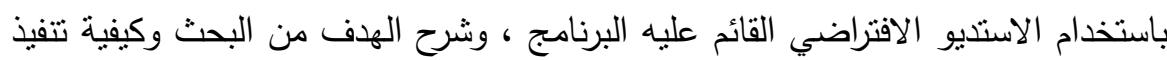

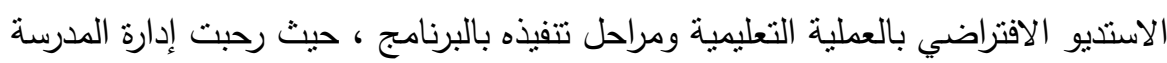

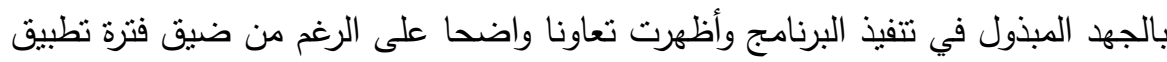

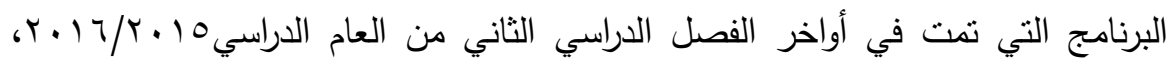

وقرب فترة امتحانات التلاميذ للفصل الدراسي الثاني وفترة استعداد الإدارة المدرسية لها.

\section{إجراءات تثفيذ البرنامج باستخدام الاستديو الافتراضي:}

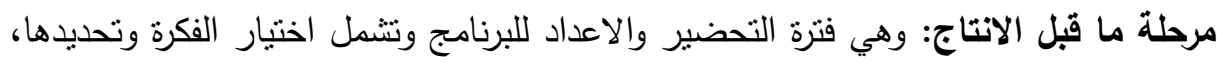
وتعد هذه الخطوة المهمة في اعداد البرنامج وهو اعطاء تصور خاص عن طريقة تتاول

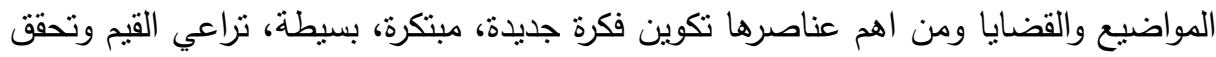

مرحلة كتابة السيناريو: وفيه نم التخيل الكامل لثكل البرنامج بكامل عناصره مكتوباً على تلى الورق تماماً كأنك تراه على الثانشة، ويشمل على الصوت والنص والصورة والمؤثر والنقلة والمشهد لكل قضية ومشكلة من القضايا والمشكلات الأربعة (تلوث الهواء، تلوث الماء، التنوع

الحيوي ، الطاقة). مرحلة الانتاج في الاستديو الافتراضي: وهي مرحلة الانتاج والتنفيذ الفعلي وتتشمل: 
وهي لغة التليفزيون في التعبير عن الرسالة الفنية، والفن يقوم بجذب انتباه المشاهد والسيطرة على حواسه ويهدف التصوير الناجح إلى تكوين رؤية ضوئية لموضوع التصوير لأن

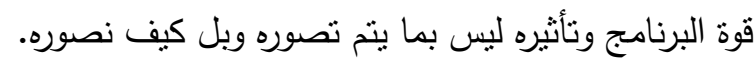

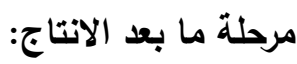
(1) تفريغ اللقطات المصورة وفهرستها وتصنيفها واختيار اللقطات على حسب ما هو مرسوم في السيناريو . r) تتفيذ عملية المونتاج: جميع اللقطات المطلوبة وتقطع وتدمج في سياق متتابع حسب السيناريو في برنامج خاص. r) دمج المؤثرات البصرية والخلفيات في خط الانتاج بالإضافة إلى رسومات الجرافيك، التعليقات. ع) دمج المؤثرات الصوتية والموسيقى التصورية. 0) تصدير البرنامج وهي المرحلة النهائية لصناعة البرنامج التليفزيوني.

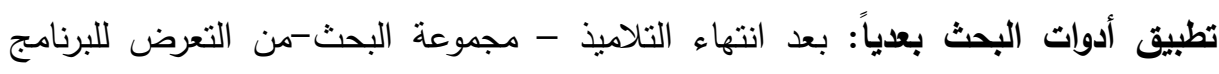
المقترح وتدارسه، قام الباحثون بإعادة تطبيق كلاً من مقياس الوعي البيئي، ومقياس المهارات البيئية على التلاميذ المجموعة البحثية (المجموعة التجريبية).

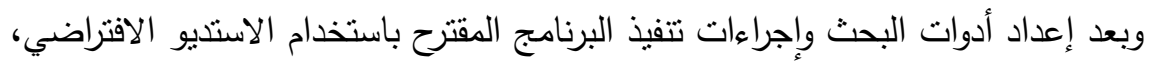
تم تقديم مجموعة من الملاحظات والموجهات يتم الاسترشاد بها للقائمين على تكنولوجيا التعليم بالمدرسة عند نطبيق البرنامج، من قبل القائمين على العملية التعليمية بمرحلة التعليم المتوسطة.

\section{نمائي الميهن}

التحقى من صحة فروض البحث:

نتائج تطبيق مقياس الوعي البيئي لتلاميذ المرحلة المتوسطة "الصف التاسع":

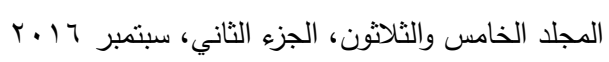


الفرض الأول: وينص على: توجد فروق ذات دلالة إحصائية بين متوسط درجات تلاميذ المجموعة التجريبية في مقياس الوعي البيئي قبل وبعد نطبيق البرنامج لصالح التطبيق

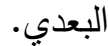

جدول(1): يوضح الفروق بين منوسطي الدرجات في الوعي البيئي للتنلاميذ

\begin{tabular}{|c|c|c|c|c|c|c|c|c|}
\hline التأثنِ & ألالة & T ت & الحرجية & $\varepsilon$ & p & القياس & الدحور & المحور \\
\hline \multirow{2}{*}{$\cdot, 70$} & \multirow{2}{*}{$\cdot, \cdots$} & \multirow{2}{*}{$r, I r$} & \multirow{2}{*}{$r q$} & $\cdot, 1 \leq \Lambda$ & $\cdot, v \leq r$ & قبلي & \multirow{2}{*}{7} & \multirow{2}{*}{ الهواء } \\
\hline & & & & $\cdot, 11 r$ & $\varepsilon, O V$ & بعدي & & \\
\hline \multirow{2}{*}{$\cdot, V Y$} & \multirow{2}{*}{$\cdot, \cdots$} & \multirow{2}{*}{$0, \leqslant V$} & \multirow{2}{*}{ rq } & $\cdot, 1 \vee q$ & $1, \wedge 9$ & قبلي & \multirow{2}{*}{7} & \multirow{2}{*}{ تلوث } \\
\hline & & & & $\cdot, .99$ & $\varepsilon, 7 \wedge$ & بعدي & & \\
\hline \multirow{2}{*}{$\cdot, V \varepsilon$} & \multirow{2}{*}{$\cdot, \cdots$} & \multirow{2}{*}{$7, r)$} & \multirow{2}{*}{ rq } & זTד, . & $1, V r$ & قبلي & \multirow{2}{*}{7} & \multirow{2}{*}{ الحيوي } \\
\hline & & & & $\cdot, 911$ & $\varepsilon, 70$ & بعدي & & \\
\hline \multirow[t]{2}{*}{$\cdot, \vee \wedge$} & \multirow{2}{*}{$\cdot, \cdots$} & \multirow[t]{2}{*}{ r,ro } & \multirow[t]{2}{*}{ rq } & $\cdot, \wedge \backslash \vee$ & $Y, O \wedge$ & قبلي & \multirow[t]{2}{*}{7} & \multirow[t]{2}{*}{ الطاقة } \\
\hline & & & & $\cdot, 9 \vee 0$ & $0, Y M$ & بعدي & & \\
\hline \multirow{2}{*}{$\cdot, V Y$} & \multirow{2}{*}{$\cdot, \cdots$} & \multirow{2}{*}{$1 \leqslant, \cdot 7$} & \multirow{2}{*}{ rq } & $\cdot, \varepsilon \varepsilon$ & 7,9 & قبلى & \multirow{2}{*}{$r \varepsilon$} & \multirow{2}{*}{ المجموع } \\
\hline & & & & $\cdot, 0 Y$ & 19,11 & بعدي & & \\
\hline
\end{tabular}

يتضح من النتائج الموضحة بالجدول السابق أنه توجد فروق ذات دلالة احصائية بين

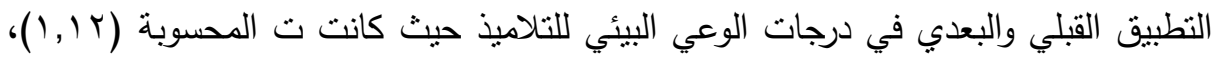

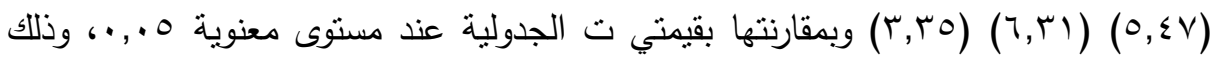
عند درجة حرية 9 و، فوجد أن قيمة ت المحسوبة أكبر من ت الجدولية حيث كان منوسط

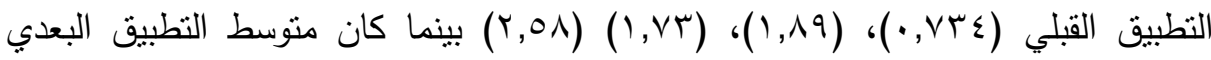

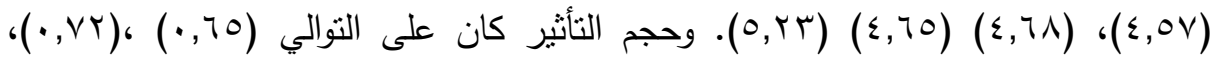

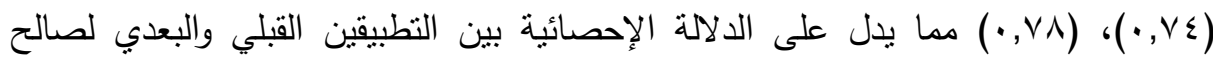
التطبيق البعدي؛ الأمر الذي يعني تحقق صدق الفرض التجريبي الاول. 
وهذا يدل على أن تطبيق البرنامج المقترح كان لها الأثر الدال في إكساب التلاميذ الوعي

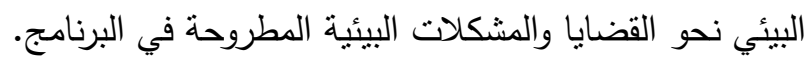

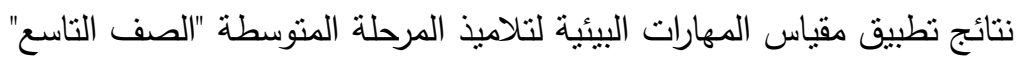
الفرض الثاني: وينص على: "توجد فروق ذات دلالة إحصائية في متوسط درجات تلاميذ المجموعة التجريبية في مقياس المهارات البيئية قبل وبعد نطبيق البرنامج لصالح التطبيق

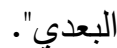

جدول(r): الفروق بين متوسطي الدرجات في المهارات البيئية

\begin{tabular}{|c|c|c|c|c|c|c|c|c|}
\hline التأثني & 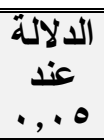 & T & الحريةت & $\varepsilon$ & p & القياس & البعد & الأبعاد \\
\hline \multirow{2}{*}{$\cdot, v_{1}$} & \multirow{2}{*}{$\cdot, \cdot$} & \multirow[t]{2}{*}{$r, \varepsilon \varepsilon$} & \multirow[t]{2}{*}{ rq } & $\cdot, 97$ & $\varepsilon, Y \mu$ & قبلي & \multirow[t]{2}{*}{ IV } & \multirow{2}{*}{ إلدراك وتحديد البئلات } \\
\hline & & & & $\cdot, \vee \leqslant$ & IY,YK & بعدي & & \\
\hline \multirow{2}{*}{$\cdot, 9$. } & \multirow{2}{*}{$\cdot, \cdots$} & \multirow{2}{*}{$r, 11$} & \multirow{2}{*}{ rq } & ס ז, & 1,9 & قبلي & \multirow{2}{*}{ V } & \multirow{2}{*}{ والبيانات البيائية } \\
\hline & & & & $\cdot, \sum \wedge$ & 0,17 & بعدي & & \\
\hline \multirow{2}{*}{$\cdot, 91$} & \multirow{2}{*}{$\cdot, \cdots$} & \multirow{2}{*}{$\varepsilon, \wedge r$} & \multirow{2}{*}{ rq } & $\cdot, \wedge \varepsilon$ & ד, 0, & قبلي & \multirow{2}{*}{$r}$. & \multirow{2}{*}{ ألمشاد الحلات } \\
\hline & & & & $1, .0$ & $17, \leqslant 0$ & بعدي & & \\
\hline
\end{tabular}

يتضح من النتائج الموضحة بالجدول السابق أنه توجد فروق ذات دلالة احصائية بين

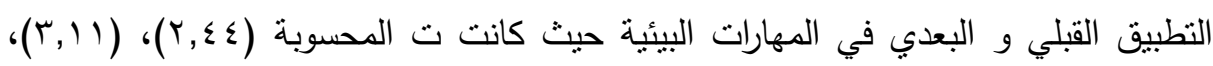

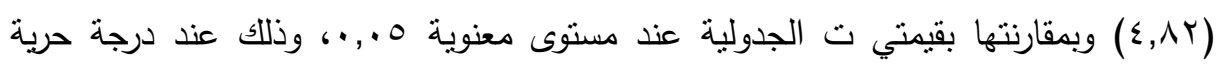

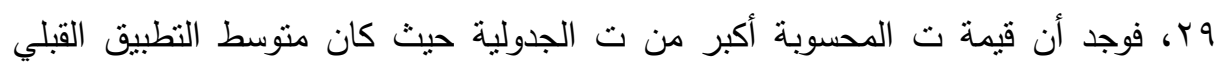

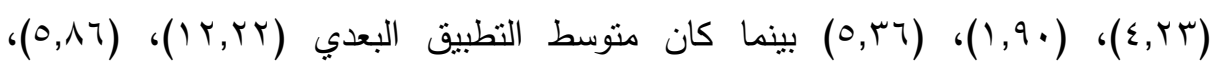

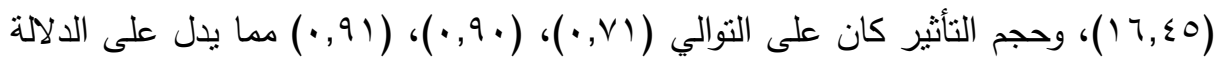


الإحصائية بين التطبيقين القبلي والبعدي لصالح التطبيق البعدي للمجموعة التجريبية؛ الأمر الذي يعني تحقق صدق الفرض التجريبي الثاني. وهذا يدل على أن تطبيق البرنامج المقترح

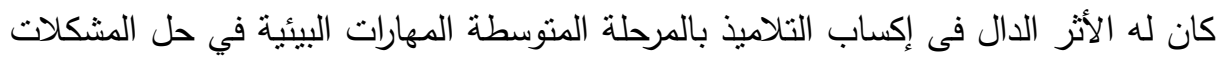
والقضايا البيئية المطروحة. فاعلية البرنامج المقترح في تنمية الوعي البيئي والمهارات البيئية: يقصد بفاعلية البرنامج

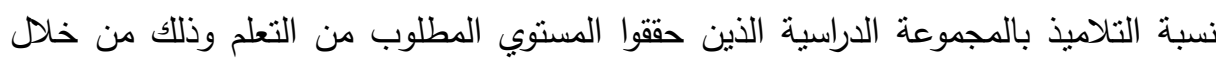
درجاتهم الكلية على مقياس الوعي البيئي، ومقياس المهارات البيئية لكل محاور المقياسين ملين لمعرفة فاعليتهما ومن ثم نكون فاعلية البرنامج المقترح لتتمية الوعي البيئي والمهارات البيئية والقائم على (استخدام الاستديو الافتراضي) أعلي من أو تساوي الواحد الصحيح كما تقيسها معادلة نسبة الكسب المعدل لبلاك. جدول(r): نتائج نسبة الكسب المعدل لبلاك بين المتوسط القبلي والبعدي لمقياس الوعي

\begin{tabular}{|c|c|c|c|c|c|c|}
\hline \multirow{4}{*}{ مستوي } & \multirow{3}{*}{ الكسبة } & & & & & \\
\hline & & \multicolumn{2}{|c|}{ متوسط الدرجات } & \multirow{2}{*}{ اللنهائية } & \multirow{2}{*}{\multicolumn{2}{|c|}{ المقياس / المحور }} \\
\hline & & \multirow{2}{*}{ بعدي } & \multirow{2}{*}{ قبلي } & & & \\
\hline & $1, \pi$ & & & 7 & تلوث الهواء & \multirow{4}{*}{ البيئي } \\
\hline مقبول & $1,1 \varepsilon$ & $\varepsilon, 7 \wedge$ & $1, \wedge 9$ & 7 & تلوث المياه & \\
\hline مقبول & 1,11 & $\varepsilon, 70$ & $1, V r$ & 7 & النتوع الحيوي & \\
\hline مقبول & $1, Y_{1}$ & $0, Y \mu$ & T,OA & 7 & الطاقة & \\
\hline فعال & $1, Y Y$ & $\varepsilon, \vee \wedge$ & $1, V \mu$ & $T \xi$ & ع ع الكلى & \\
\hline
\end{tabular}


جدول(؛ ): نتائج نسبة الكسب المعدل لبلاك (الفاعلية) بين متوسطات القبلي والبعدي لمقياس المهارات البيئية

\begin{tabular}{|c|c|c|c|c|c|c|}
\hline \multirow{2}{*}{ مستوي } & \multirow{2}{*}{ الكسبة } & \multicolumn{2}{|c|}{ متوسط الارجات } & الارجة. & \multirow{2}{*}{\multicolumn{2}{|c|}{ المقياس / المحور }} \\
\hline & & بعدي & قبلي & للمحوز & & \\
\hline مقبول & $1, \cdot 9$ & $I r, r Y$ & $\varepsilon, r T$ & IV & المشكلات وتحديدية & \multirow{3}{*}{ المهارات } \\
\hline مقبول & r & $0, \wedge 7$ & $1,9$. & V & تتظيمي المعلومات البياتية & \\
\hline مقبول & $1, \pi$. & $17, \leqslant 0$ & ד, 0, & r. & للششكاد الحلولئية البيأي & \\
\hline فعال & $1, Y \leqslant$ & 11,01 & $r, \wedge r$ & $\varepsilon \varepsilon$ & موع الكلح & \\
\hline
\end{tabular}

ويتبين من نتائج جدول (ץ)، (ع) أن نسبة الكسب المعدل لبلاك للمجموعة التجريبية

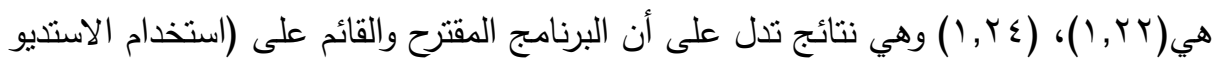

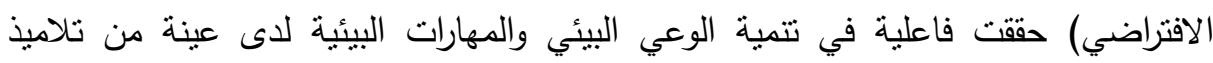
المدارس بالمرحلة المتوسطة "الصف التاسع" في دولة الكويت. ومن ثم يمكن القول بأن البرنامج الذي تم تجريبه على التلاميذ له فاعلية بشكل واضح في تتمية الوعي البيئي والمهارات البيئية.

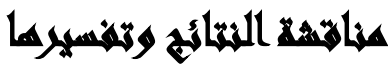

ه أوضحت النتائج أن هناك فروق في المتوسطات بين التطبيقين القبلي والبعدي للمجموعة التجريبية على كل محاور مقياس الوعي البيئي للأربع قضايا والمشكلات البيئية المطروحة فئئي

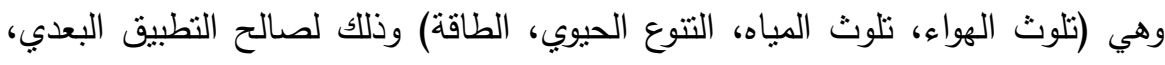
مما يدل على حدوث تحسن لدى تلاميذ المجموعة البحثية نتيجة مشاركتهم فى البرنامج المقترح. • وكذللك بمقارنة النتائج بين تطبيق مقياس المهارات البيئية القبلي والبعدي للتناميذ في

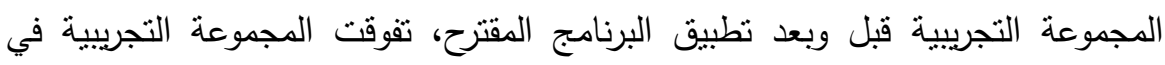

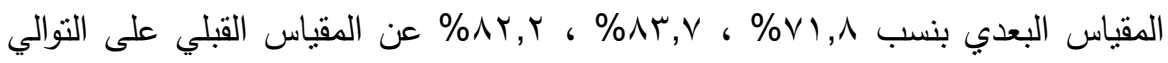


في المهارات البيئية الثلاث (إدرالك وتحديد المشكلات البيئية، تتظيم المعلومات والبيانات البيئية، إيجاد الحلول للمشكلات البيئية)، واتضح ذلك بوجود فروق ذات دلالة إحصائية بين منوسط درجات المقياس البعدي والقبلي عند مسنوى دلالة هـ ـ.

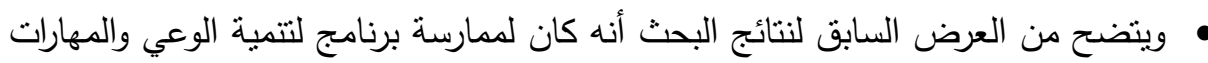
البيئية باستخدام الاستديو الافتراضي آثره في ارتفاع متوسط درجات المجموعة التجريبية

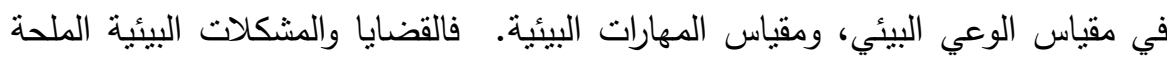
كانت منتوعة في موضوعاتها. حيث حاول الباحثون التتوع في موضوعات البرنامج ليشمل مكونات مقياس الوعي البيئي ومقياس المهارات البيئية المختلفة وأدى هذا التتوع إلى ارتفاع

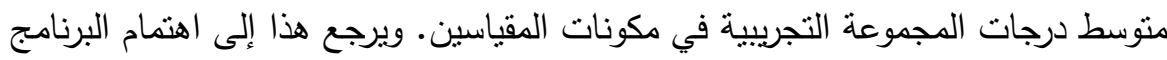

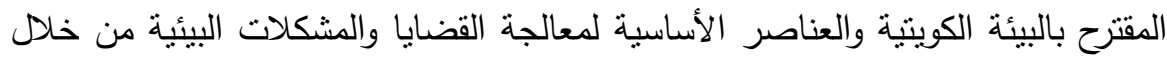

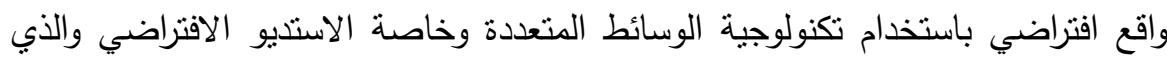
ساهم في زيادة فاعلية تدريس البرنامج في هذا الجانب، لبساطة عرضه وجذانبه للتلاميذ

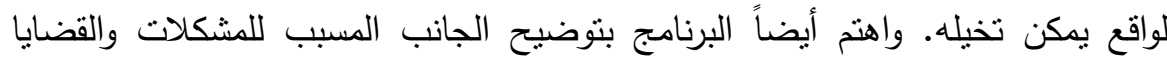
المطروحة، مما كان له آثزه أيضاً في زيادة الفرق بين متوسطى درجات تلاميذ المجموعة بلهاب

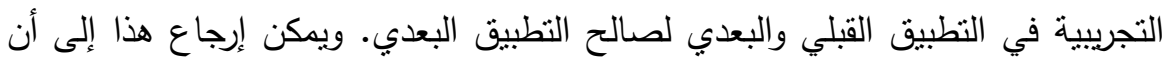

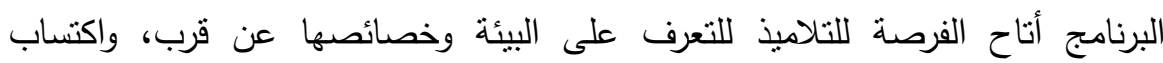
معلومات بيئية صحيحة، جعلت هؤلاء التلاميذ يصدرون حلولاً صحيحة على مشكلات البيئة المحيطة بهر. تثفق نتائج البحث الحالي مع نتائج الدراسات والبحوث السابقة، من حيث دور الأساليب

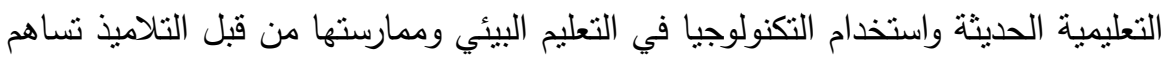
بشكل فعال في تتمية الوعي البيئي والمهارات البيئية وكيفية التعامل مع المشكلات البيئية، وهذا بدوره يسهم بشكل إيجابي في تحقيق أهداف التربية البيئية بشكل عام، ومن هذه

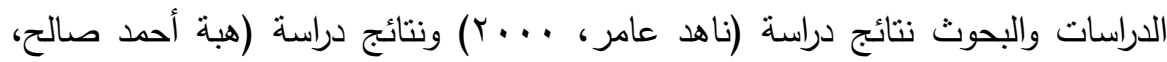




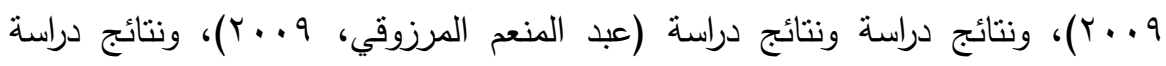

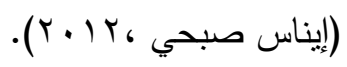

\section{تمكياهت المهيد}

1-تطبيق البرنامج المقترح كي يساهم في تتمية الوعي البيئي والمهارات البيئية لتلاميذ المرحلة

$$
\text { المتوسطة. }
$$

r-التخلي عن الطرق التقليدية للتدريس والاستعانة بالوسائل التكنولوجية باستخدام الاستخيو

$$
\text { الافتراضي لمساعدة التلاميذ لتحقيق النتائج المرجوة من التعليم البيئي. }
$$

r-تعميم تجربة الاستديو الافتراضي على جميع المدار والمؤسسات التعليمية لتحقيق لهيق

$$
\text { الأهداف التربوية (المعرفية، الوجدانية، المهارية) تجاه البيئة. }
$$

ع - التعاون بين وزارة التربية والهيئة العامة للبيئة لوضع خطة متكاملة للمساهمة فى تتمية

$$
\text { وعي ومهارات التلاميذ نحو بيئتهم. }
$$

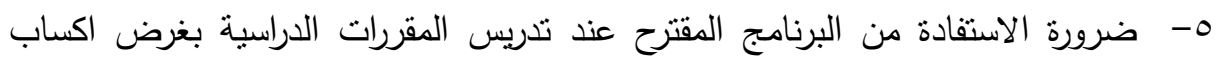
الافراد مهارات انتاج برمجيات الواقع الافتراضي التعليمية لمعالجة المشكلات البيئية

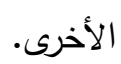

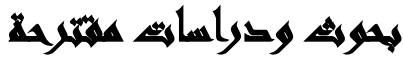

في ضوء إجراءات ونتائج البحث الحالي يقترح إجراءات دراسات وبحوث في المجالات التالية منل:- برنامج مقترح قائم على استخدام الاستديو الافتراضي لتتمية المسئولية البيئية تجاه حماية البيئة الكويتية لدى طلاب المدارس الثانوية.

- إجراء بحوث تهتم باستخدام الاستديو الافتراضي لنتمية المفاهيم والاتجاهات البيئية والسلوك البيئي لدى الطلاب في المراحل الدراسية المختلفة.

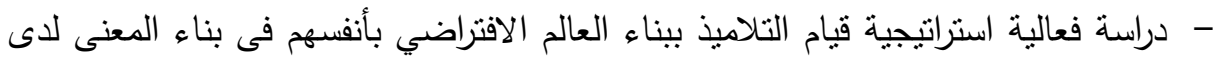
التلاميذ وأثزها كذلك على متغيرات تعليمية تابعة كالقيم البيئية واكتساب المهارات البيئية.

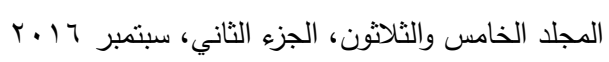


- دراسة تأثثر بيئات الاستديو الافتراضي للمناهج الدراسية مقابل التعلم وجها لوجه (التعلم

\section{المرانج}

إبراهيم عصدت مطاوع( ( . . ب) الثربية في الوطن العربي، دار الفكر العربي، القاهرة.

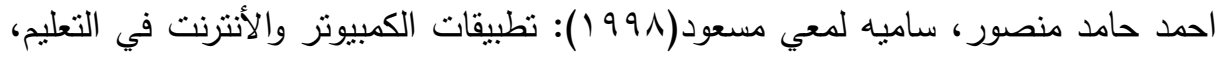

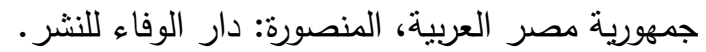

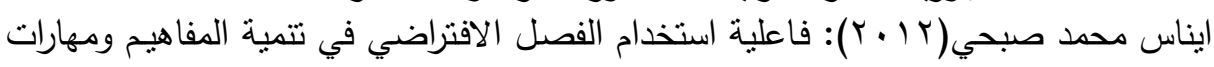

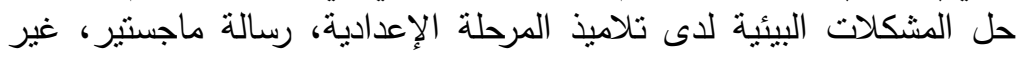

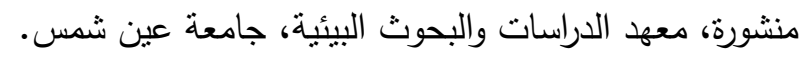

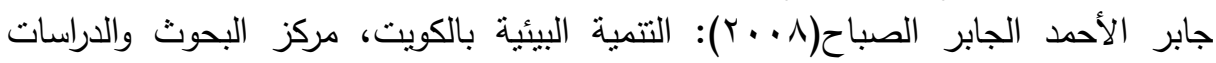

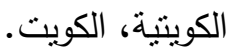

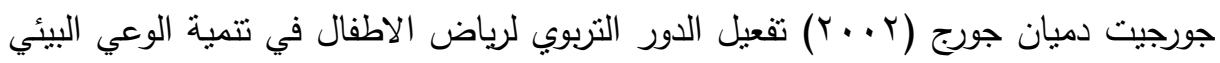

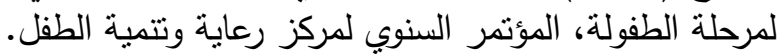

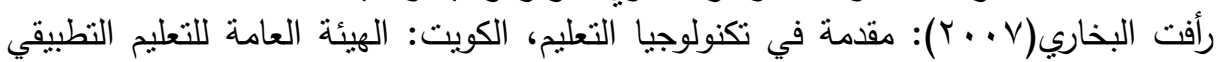

$$
\text { والتدريب } 7 .
$$

رشيد الحمد، محمد سعيد صابريني( 99 ()): الانسان والبيئة (التربية البيئية)، مكتبة الكتاني،

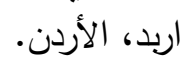

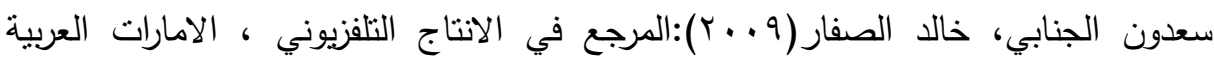

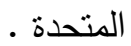

سهام بن يحي(0 . . ب): الصحافة المكتوبة وتتمية الوعي البيئي في الجزائر، رسالة ماجستير

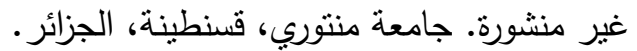

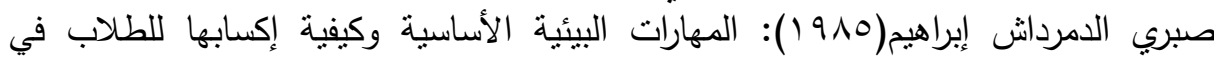

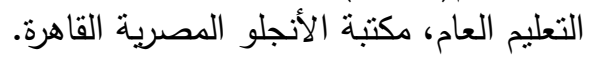

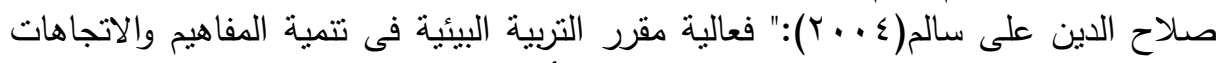

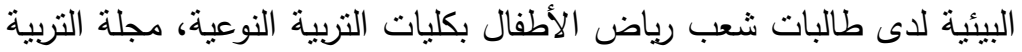

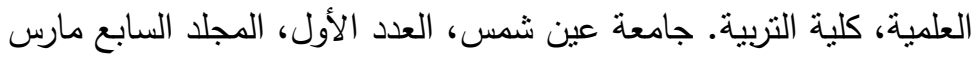

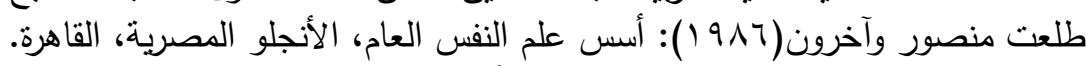

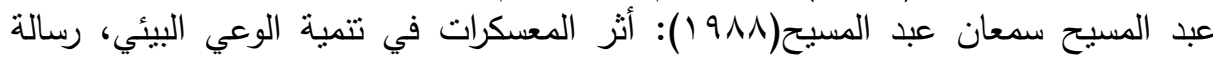

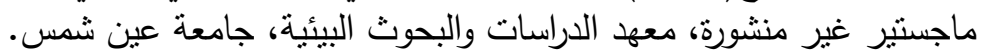

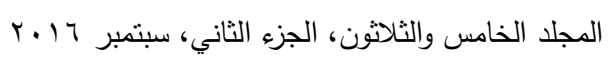


عبد المسيح سمعان عبد المسيح(ب999 () دورة دور مراكز الثباب فى تتمية الوعى البيئي، رسالة

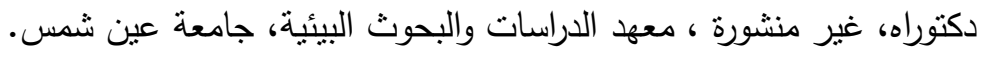

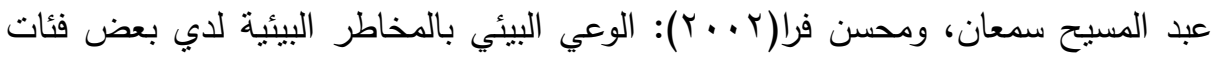

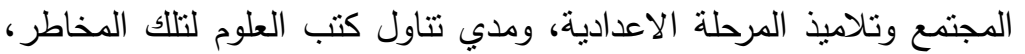

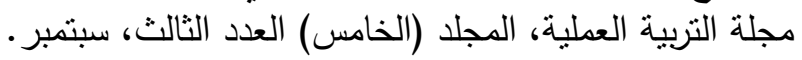

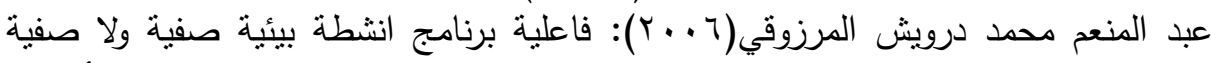

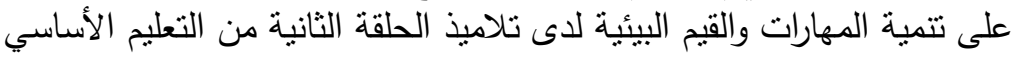

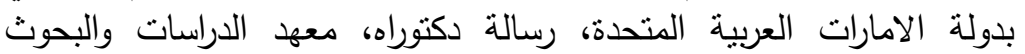

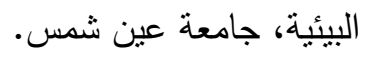

فائزة رجب محم(9 . . ب): تتمية المهارات البيئية لدي تلاميذ المدرسة الإعدادية المهنية، رسالة

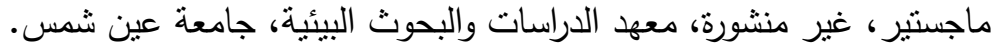

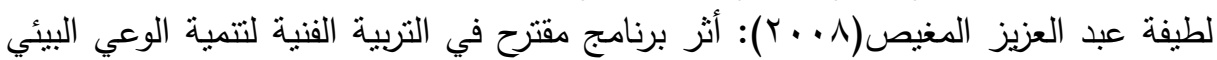

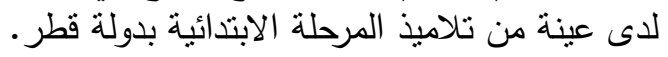

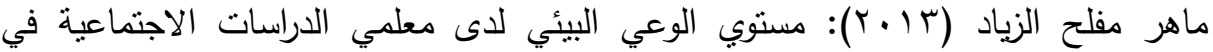

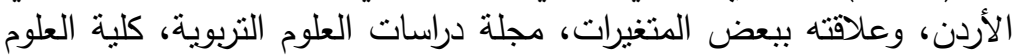

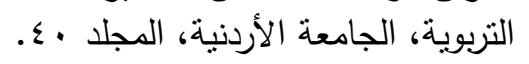

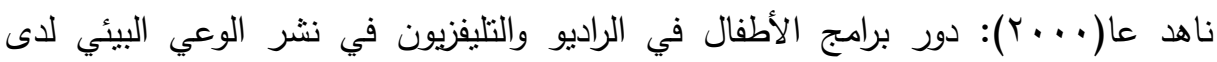

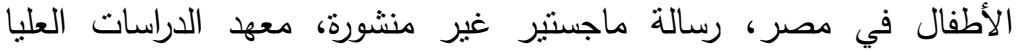
للطفولة، جامعة عين شمس.

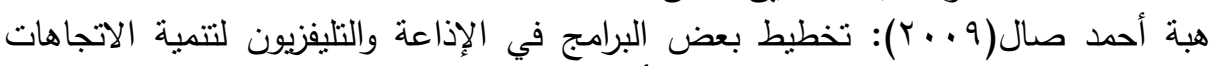

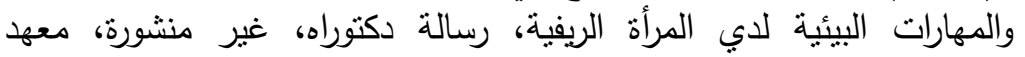

$$
\text { الدراسات والبحوث البيئية، جامعة عين شمس. لرئة }
$$

Goldensan RU.,(1984):"London Dictionary of Psychology and Psychiatry (New York, London, 1984, p. 181.

Griggs and Karen (2001): Environmental problem - Solving in communication courses. Vol . 48 , p, 40 .

Menuka, Gupta and Kai Huttemann (2010): Education with itv, fraunhofer institute for media communication competence center, Itv schlob birling oven ,53754 sankt Augustin , Germany,p.111

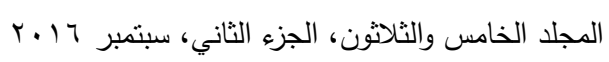




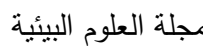

معهد الدراسات والبحوث البيئية - جامعة عين شمس البرس

\title{
THE EFFECTIVENESS OF USING VIRTUAL STUDIO IN DEVELOPMENT OF ENVIRONMENTAL AWARENESS AND SKILLS AMONG MIDDLE STAGE STUDENTS IN KUWAIT STATE
}

\begin{abstract}
Abdel Meseh, S. A. ${ }^{(1)}$; El-Mineefi, G. M. ${ }^{(2)}$ and Malek, T. A. ${ }^{(3)}$
1) Institute of Environmental Studies and Research, Ain Shams University 2) Faculty of Basic Education, The Public Authority for Applied Education and Training, Kuwait 3) The Ministry of Justice, Kuwait
\end{abstract}

\begin{abstract}
The research aims to development of environmental awareness and environmental skills among middle school students in Kuwait through the proposed program included some urgent issues and problems in the State of Kuwait, and prepare a list of issues and environmental problems, namely through the literature and previous research and studies and experts and specialists: issues and problems of environmental pollution (air, water), the issue of maintaining the "biodiversity", the issue of maintaining the "energy" and its development.

Then prepare and Design Studio based in learning, and includes pre-production, production, post production, and contains four issues (air pollution, water pollution, biodiversity, energy) and that have been identified and their knowledge through their survey researchers to identify pressing environmental issues and problems in the State of Kuwait, Scales were also prepared for environmental awareness and environmental skills, be a measure of environmental awareness 24 476

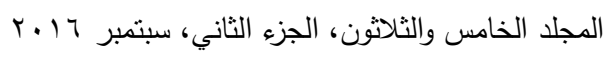


words about issues and problems; environmental skills scale 34 words and attitude through three skills are: recognize and identify environmental problem. Organize information and environmental data. Solutions to environmental problems.

Research group consisted of 30 students in the ninth grade in middle school in the Kuwait. Search results: referred to the effectiveness of the program and had an impact on the development of environmental awareness and environmental skills for these pupils. 